\title{
OUVIR O "GRITO" DE FRANS KRAJCBERG: REVERBERAR SUA LUTA
}

Listen the Frans Krajcberg's "Cry": reverberating his struggle

Escuchar el "Grito" de Frans Krajcberg: reverberar su lucha

$>$ Luciana Benetti Marques Válio [UNICAMP, Brasil]

Citação recomendada:
VAlı̈, Luciana Benetti
Marques. Ouvir o "grito"
de Frans Krajcberg: re-
verberar sua luta. Revista
Poiésis, Niterói, v. 22,
n. 38, p. 106- 120, jul./
dez. 2021 . [https://doi.
org/10.22409/poiesis.
v22i38.45674 ] Este
documento é distribuído
nos termos da licença
Creative Commons
Atribuição-NãoComer-
cial 4.0 Internacional
[CC-BY-NC]
(C) 2021 Luciana Benetti
Marques Valio.

(Submetido: 31/8/2020; Aceito: 7/1/2021: Publicado: 7/7/2021)
RESUMO A abordagem da obra de Frans Krajcberg neste artigo será realizada considerando a urgência do momento atual da pandemia do coronavírus. A partir de reflexões sobre a crise climática produzida em função das devastações das florestas, diante da possibilidade de chegada ao fim do mundo, falar da obra de Krajcberg é mais do que homenageá-lo, é uma maneira de procurarmos resistir à destruição que se apresenta cada vez mais vultosa. Assim, unir-se à voz de Krajcberg em defesa da Floresta Amazônica e de seus povos é uma forma ajudar a levar adiante sua luta e estabelecer possibilidades de sobrevivência e resistência. PALAVRAS-CHAVE Frans Krajcberg, arte e natureza, Bienal de São Paulo

ABSTRACT In this paper, the approach of Frans Krajcberg's artwork will be carried out considering the urgency of current moment of the coronavirus pandemic. Based on reflections about the climatic crisis produced due to the deforestation of the forests, facing the possibility of reaching the end of the world, talking about Krajcberg's artwork is more than honoring him, it is the way for us to resist the destruction which is taking place, presents more and more large. Thus, joining to Krajcberg's cries in defense of the Amazon Forest and its indigenous people is a way to help carry out his struggle and establish possibilities for survival and resistance. KEYWORDS Frans Krajcberg, art and nature, Bienal de São Paulo

RESUMEN En este artículo, el planteamiento del trabajo de Frans Krajcberg se llevará a cabo considerando la urgencia del momento actual de la pandemia del coronavirus. A partir de reflexiones sobre la crisis climática producida por la deforestación de los bosques, ante la posibilidad de llegar al fin del mundo, hablar del trabajo de Krajcberg es más que honrarlo, es una forma de resistir la destrucción que se está produciendo, cada vez más grande. Por lo tanto, unirnos a la voz de Krajcberg en defensa de la selva amazónica y su gente es una forma de ayudar a llevar adelante su lucha y establecer posibilidades de supervivencia y resistencia. PALABRAS CLAVE Frans Krajcberg, arte y naturaleza, Bienal de São Paulo

* Luciana Benetti Marques Válio é Pós-Doutoranda do Programa de Pós-Graduação em Artes Visuais da UNICAMP. E-mail: luvalio@yahoo.com 
Frans atendeu o chamado

e entendeu o seu destino,

que perseverante cumpre

com amor e indignação.

É a sua parte, sua maneira

luminosa de servir

mais que à vida da floresta.

à do homem que vive nela

à do homem que vive dela.

Não é grito de guariba

não é esturro de onça, nem silvo do Curupira.

É a mata pedindo ajuda.

A floresta é a tua casa,

Cuida dela com amor

Thiago de Melo

\section{APRESENTAÇÃO E CONTEXTO ATUAL}

Escrever mais um artigo sobre Frans Krajcberg requer uma explicação sobre sua necessidade? Krajcberg, além de consagrado nacional e internacionalmente enquanto artista, também reconhecido por sua atuação ambientalista, tem sua obra/ vida vastamente documentada e descrita tanto em artigos acadêmicos, teses e dissertações como em reportagens na mídia, documentários/filmes, catálogos de exposições e demais publicações.
Apesar de tanto ser dito sobre ele, de maneira densa e instigante, parece que neste momento há uma urgência de que sua obra seja mais e mais enfatizada, para que seu "grito" de revolta, seu clamor por um cuidado pela Natureza e pelos Povos da Floresta, possa ser ouvido aos quatro cantos do mundo. Assim, falar da obra de Krajcberg, unir-se à sua voz em defesa da Floresta Amazônica e de seus povos, é uma forma de homenagear sua memória e ajudar a levar adiante sua luta.

A importância da discussão sobre a ecologia nas práticas contemporâneas das artes visuais torna-se cada vez mais intensa, porém, exatamente por causa de sua dissolução nessa poética, sua potência muita [sic] vezes é dissimulada, confundida ou simplesmente não identificada. Entretanto, é neste ponto que a obra de Krajcberg encontra o seu mais alto grau de permanência. Agente infiltrador, portador de questionamentos, defensor da natureza e de suas possibilidades de encontro e diálogo com a arte, a obra de Krajcberg representa um marco na investigação sobre o espaço e o uso que o homem faz dele. [SCOVINO,

2011, p. 45-47].

Na 32ªienal de São Paulo, em 2016, os trabalhos de Krajcberg marcaram a exposição enfatizando o caráter ecológico da proposta curatorial do evento.

$\bigcirc$ grito de Frans Krajcberg na defesa das florestas ecoa entre as 340 obras que povoam a 32 Bienal de São Paulo. Aos 95 anos, o artista plástico polonês, que está 
no Brasil desde 1950, fez uma exigência. Participaria sim mas desde que o evento saísse na defesa das florestas, do território indígena e da vida do planeta. [...] "Onde está a arte?", questiona. "É importante mostrar a barbárie contra - planeta. Lutar e alertar sobre a salvação da Amazônia. [KIYOMURA, 2016]

Com isso, o visitante da exposição, ao adentrar no Pavilhão da Bienal, foi confrontado com a floresta de Bailarinas, Coqueiros e Gordinhos, denominações dadas aos trabalhos artísticos de Krajcberg da década de 1970-80, apresentados na 32a edição. [Fig. 1] O conjunto dos trabalhos estabeleceu um diálogo entre o dentro e o fora do espaço arquitetônico, como se as árvores do Parque Ibirapuera contracenassem com a paisagem de Krajcberg, reforçando mais ainda o contraste. Tal impacto intencional foi elaborado a partir da proposta curatorial sob o título de Incerteza Viva, como uma provocação para refletirmos sobre as incertezas do momento. Para essa edição da Bienal, Krajcberg faz um apelo: "Bienal a favor da saúde do Planeta. Bienal de São Paulo." [KRAJCBERG, 2016].

No caso, em 2016, mal se imaginava que as incertezas eram apenas um prenúncio do período do que viveríamos hoje, em 2020. O curador da mostra, o alemão erradicado no Brasil Jochen Volz, fundamentou seus discursos em diversos autores que abordaram o tema da incerteza. Porém, ele justificou sua escolha pelo tema diante do que constatou, no ano de 2014, quanto às publicações de enfoque direcionado às problemáticas decorrentes das alterações climáticas, as quais alertavam sobre os impactos do antropoceno².

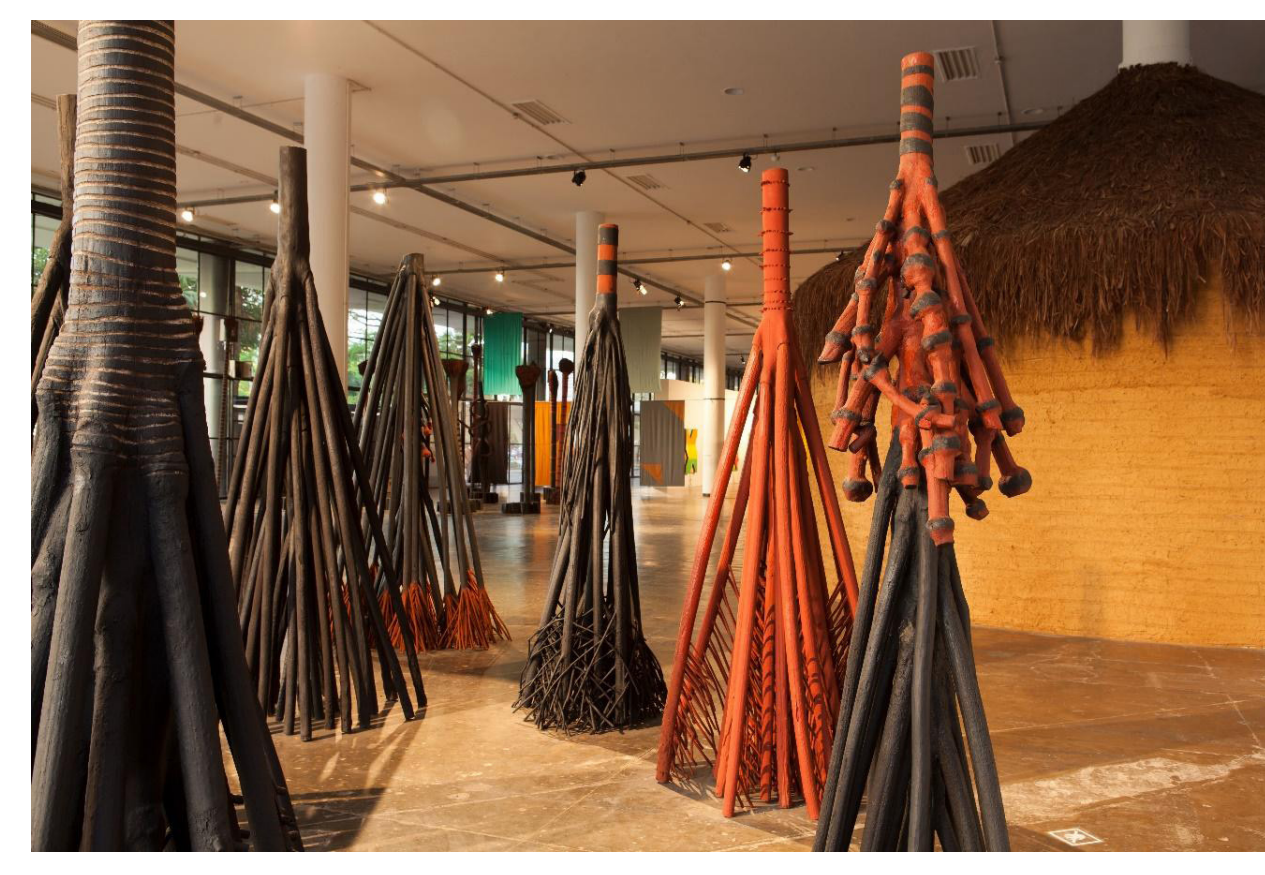

Fig. 1-Franz Krajcberg, Sem título [Bailarinas], s.d. Esculturas de madeira de queimada e pigmentos naturais. 10 peças, dimensões variadas.

Fonte: Pedro Ivo Trasferetti, cortesia Fundação Bienal de São Paulo. 
Dentre as publicações, apresenta-se aqui o livro de Déborah Danowski e Eduardo Viveiros de Castro, Há um mundo por vir? Ensaio sobre os medos e os fins, no qual os autores discorrem sobre o conceito de fim de mundo, analisando como a crise climática e as alterações no planeta provocadas pela ação humana podem ter explicações de diferentes pontos de vista. Assim, discutindo a partir dos pensamentos de Bruno Latour, Isabelle Stengers, entre outros, os autores nos convidam a olhar outras formas de compreensão do mundo, e como nós mesmos [ocidentais, modernos] nos deparamos com o mundo que se encontra hoje. Apresentando outras perspectivas, abrem possibilidades para acolhermos outras cosmovisões.

De maneira geral, a 32a Bienal de São Paulo, em 2016, insistiu fortemente em sua proposta curatorial nas questões ambientais, com enfoque nas questões vinculadas à destruição da floresta Amazônica. Buscou enfatizar a relação entre arte e natureza, principalmente, por meio de referências e alusões aos povos indígenas. Assim, partindo da premissa da Incerteza Viva, Volz [2016b] propôs

a incerteza como pertencente aos mais diversos campos da vida, ainda mais ao considerarmos que "as dimensões de como vivenciamos a incerteza se ampliaram radicalmente no curso da última década, em virtude do maior entendimento de um mundo globalizado." [VOLZ, 2016b, p. 7]. Sobretudo, agora, na globalização em situação de pandemia. Tal análise das incertezas de 2016 ressoa nos dias atuais e torna-se realidade à medida que os anúncios das catástrofes biológicas, das crises políticas e econômicas, das guerras, da fome e da miséria humanas presentificam-se num contexto de pandemia do Covid-19.

O contexto atual, já previsível em 2016, é abordado no evento: "Ainda que prognósticos de eventos futuros no planeta apresentem contradições, cientistas de todas as disciplinas clamam por ação imediata e pedem que a consciência coletiva se eleve em todo o planeta para enfrentar os desafios com que as sociedades se deparam nesse momento." [VOLZ, 2016b, p. 8]. Estudos sobre possíveis pandemias já alertavam que o modo produtivo da agroindústria levaria à disseminação de novos vírus. Contudo, foram desacreditados, como no caso do pesquisador Rob Wallace ${ }^{3}$, por afrontar os interesses dessas indústrias, ao insistir nos alertas de perigos decorrentes da perda da biodiversidade, que ampliam as chances de surgimento de novos patógenos ${ }^{4}$.

Krajcberg, por meio de sua obra, manifestava sua revolta contra a destruição da biodiversidade, em função dos interesses econômicos e extrativistas. Ele, como outros artistas na 32ª Bienal, reuniram aquilo que Volz [2016a] descreveu como "uma in- 
vestigação para encontrar o pensamento cosmológico, a inteligência ambiental e coletiva e a ecologia sistêmica e natural." [VOLZ, 2016a, p. 23]. Nesta busca, segundo o curador, "as obras de arte representam uma visão de mundo, e levadas a sério, podem oferecer a todos ferramentas e estratégias alternativas para uma vida na incerteza" [VOLZ, 2016 b, p. 10]. O curador entende a proposta da mostra como um disparador, ou desestabilizador, ou um estímulo às alternativas que ultrapassam o campo da arte, ou seja, trata-se "[d]os inúmeros métodos de raciocinar e de fazer da arte e aplicá-los a outros campos da vida pública." [VOLZ, 2016 b, p. 10]. Se, em 2016, o contexto geral possibilitava que a Bienal se intitulasse de Incerteza Viva, a edição de 2020 apropria-se de um verso do poeta amazonense Thiago de Mello e lança como título do evento a frase Faz escuro mas eu canto.
Faz escuro mas eu canto é um tema que se encaixa perfeitamente no momento da pandemia atual, mais especificamente em relação aos desmatamentos e às queimadas da Floresta Amazônica e Pantanal. Essa frase remete à resiliência e à resistência não somente dos povos indígenas, que estão sendo fortemente atingidos pela falta de política de proteção às suas terras, suas culturas e suas vidas, mas a todos aqueles que de alguma maneira compartilham do desejo de um mundo mais justo, que privilegie a biodiversidade, com florestas e águas limpas e seus povos originais cuidando delas. Manter a utopia, a que Thiago de Mello se refere, é resistir e sobreviver.

Danowski e Viveiros de Castro [2014] descrevem as diversas compreensões de mundo que os povos originais têm sobre o fim do mundo. Além disso, os autores discutem os termos "Humanos" e "Terranos" e os relacionam com o conceito de "Modernos", de Latour, tudo isso para apresen-

Encarado mais como uma afirmação que como um tema, o título da 34º Bienal de São Paulo, Faz escuro mas eu canto, é um verso do poeta Thiago de Mello, publicado em livro homônimo do autor em 1965. Em sua obra, o poeta amazonense fala de maneira clara dos problemas e das esperanças de milhões de homens e mulheres ao redor do mundo: "A esperança é universal, as desigualdades sociais são universais também [...]. Estamos num momento em que o apocalipse está ganhando da utopia. Faz tempo que fiz a opção: entre o apocalipse e a utopia, eu fico com a utopia", afirma o escritor. Crivelli Visconti completa: "por meio de seu título, a 34ํㅡㄹenal reconhece o estado de angústia do mundo contemporâneo enquanto realça a possibilidade de existência da arte como um gesto de resiliência, esperança e comunicação". [34“ BIENAL DE SÃO PAULO, 2019] tar como os modos de viver dos mais diversos povos, apesar de todas as atrocidades cometidas pelos "Humanos", estabelecem-se como imaginários sobre o fim do mundo ou os fins dos mundos. 
Se a América indígena dos séculos XVI e XVII, representou, para os Humanos que a invadiram, um mundo sem homens - fosse porque eles a despovoaram objetivamente, fosse porque os homens que eles encontraram ali não se enquadravam na categoria dos "Humanos" -, os índios sobreviventes, os Terranos de pleno direito daquele Novo Mundo, se viram, reciprocamente, como homens sem mundo, náufragos, refugiados, inquilinos precários de um mundo a que eles não mais podiam pertencer, pois ele não mais thes pertencia. $E$ não obstante, eis que muitos deles sobreviveram. Passaram a viver em um outro mundo, um mundo de outros, de seus invasores e senhores. Alguns desses náufragos se adaptaram e "modernizaram", mas em geral de maneiras que pouco têm a ver com o que os Modernos entendem por isso; outros lutam por manter o pouco de mundo que thes restou, e esperam que, enquanto isso, os Brancos não acabem por destruir o mundo deles mesmos, dos Brancos, agora tornado o "mundo comum" - em um sentido nada latouriano da expressão - de todos os seres vivos. [DANOWSKI; VIVEIROS DE CASTRO, 2014, p. 139-140] mundo, de serem reduzidos a um campesinato pobre e oprimido" e ainda assim "sua população aumenta, sua língua floresce, seu mundo resiste, diminuído mas irredento" [DANOWSKI; VIVEIROS DE CASTRO, 2014, p. 141]. Assim, ao viver na pele o fim do mundo, os Maya resistem e talvez Discorrendo sobre as possibilidades de sobrevivência, leia-se também de resistência, dos povos originais, sem perder de vista que [... "é certo que o genocídio americano dos séculos XVI e XVII - a maior catástrofe demográfica da história até o presente, com a possível exceção da Peste Negra - causado pelo choque com o planeta Mercadoria terá sempre um lugar garantido entre os primeiros colocados," [...]. [DANOWSKI; VIVEIROS DE CASTRO, 2014, p. 138] -, os autores enfatizam o potencial de resistência dos Maya. Principalmente, porque aquele mundo que eles conheciam ou que a eles pertencia chegou ao fim. Aliás, passaram "por sucessivos fins-de- saibam melhor se preparar ou, pelo menos, saibam como fazer para resistir a serem engolidos pelo mundo que thes nega a existência.

Estamos falando é claro, do Movimento Zapatista, esta rara revolta que é um modelo de "sustentabilidade" - sustentabilidade política também sobretudo. Os Maya, que viveram vários fins-de-mundo, nos mostram hoje como é possível viver depois do fim do mundo. Como, em suma, é possível desafiar o Estado e o Mercado, e fazer valer o direito à autodeterminação dos povos. Verdadeiros especialistas em fins do mundo, os Maya, como todos os demais povos indígenas das Américas, têm muito que nos ensinar, agora que estaem algo parecido com a América do séc. XVI: um mundo invadido, arrasado e dizimado por bárbaros estrangeiros. [...] [DANOWSKI; VIVEIROS DE CASTRO, 2014, p. 141 - 142] mos no início de um processo de transformação do planeta 
Enquanto Danowski e Viveiros de Castro [2014] delineiam um exemplo de resistência, sobretudo aos interesses capitalistas do Estado-Mercado, há os que acham que resistir ao fim do mundo implica em comprar um Bunker ou uma ilha deserta para sobreviver a possiveis futuras pandemias e/ ou guerras [nucleares e/ou biológicas] ${ }^{5}$. Assim, a tecnologia de ponta poderá salvar os poucos bilionários, caso a destruição em massa venha a se realizar no planeta. Com isso, somas extraordinárias são investidas em Bunkers de luxo para garantir refúgio em tempos apocalípticos. Imagem bizarra, de assustador individualismo, alarmante sobre o comportamento de muitos dos responsáveis pela destruição da Floresta Amazônica. Refiro-me, obviamente, àqueles exploradores de minérios, pecuaristas e produtores de soja, os quais usurpam terras de floresta para beneficiar-se com sua destruição e enriquecerem diante da exploração da natureza e dos povos ${ }^{6}$.

\section{A Floresta Amazônica neste cenário ganha mais} importância, se ainda for possivel dizer isso, devido à sua biodiversidade, que é justamente o maior fator para barrar e evitar a disseminação, ou a mutação, de novos vírus pandêmicos. Desnecessário repetir sobre toda a sua importância ecológica num sistema de manutenção da temperatura, sequestro de carbono e chuvas do sistema planetário. Há uma relação sistêmica do meio ambiente; é fato que as queimadas na Amazônia afetam de maneira incisiva nos efeitos climáticos. Tanto que anoiteceu na cidade de São Paulo em plena tarde, em agosto de 2019, quando uma nuvem preta de fuligem da queimada da floresta foi desabar na grande cidade, fazendo o escuro ${ }^{7}$. Diante disso, como cantar?

Enfim, muitas incertezas permeiam o momento atual. Tão pouco ainda se sabe sobre quantos ainda irão morrer de Covid-19, ou de futuras pandemias decorrentes das atividades exploratórias humanas, assim como pouco se tem feito para reduzir a destruição dos biomas brasileiros. Isso posto, resistir, "gritar" e cantar mostram-se como ações urgentes para se manter presente neste planeta que faz escuro. Mas eu canto!

\section{FRANS KRAJCBERG: A TRAJETÓRIA ARTÍSTICA DE UM AMBIENTALISTA}

Se a edição atual da Bienal de São Paulo é convidativa ao canto, Krajcberg, ao longo de sua vida, insistiu em seu "grito". De ambas as maneiras, o convite é à ação. À ação imediata para a proteção da Floresta Amazônica. Ainda que o cantar pareça inofensivo perto do "grito", ambos mostram-se pertinentes neste momento. 
[...] $\bigcirc$ verso de Thiago de Mello tem nos acompanhado através do aparentemente interminável estado de emergência que vivemos nos últimos anos. Ressoou com novos sentidos sob a luz fatal dos incêndios na Amazônia, pano de fundo trágico e premonitório para as manifestações que se espalharam pelo mundo contra a persistência de formas estruturais de racismo e preconceito, da desigualdade, de modelos de desenvolvimento não sustentáveis e da destruição programática do planeta como o conhecemos. $\bigcirc$ verso parece ainda mais apropriado agora, diante do novo coronavírus que torna essa realidade mais evidente e extrema. Agora, mais do que nunca, não podemos nos esquivar de olhar atentamente para dentro da escuridão de nossos tempos. Mesmo atravessá-los com os olhos bem abertos talvez não seja suficiente. Queremos transformar essa travessia em uma canção - uma canção que pode ser solitária ou coletiva, sussurrada ou gritada. E não nos deixemos enganar, é preciso coragem e força para cantar agora, junto e apesar de um mundo que parece dar tão pouco valor à vida de tantos, que segue desconsiderando obscenamente o bem comum em prol da manutenção de privilégios individuais. [VISCONTI; MIYADA; ZACCAGNINI; STOCCHI; ESTÉVEZ, 2020] nica para a criação de gado, plantio de soja e exploração de minérios.

Assim, usa a sua arte como revolta contra tais ações dos seres humanos. Busca em seus trabalhos demonstrar a dramaticidade das queimadas, ao mesmo tempo em que apresenta a força e a exuberância da natureza, pois, mesmo após morta, a árvore se

Dizer que Frans Krajcberg em sua vida fez de sua obra seu grito, significa que ele teve força e coragem para fazer dela um meio para a denúncia das atrocidades contra a natureza. A partir década de 1970, ele passa também a utilizar sua obra para alertar sobre a destruição da floresta Amazônica e também de seus povos. Com seu histórico de vida, sofrido durante a $2^{a}$ Guerra Mundial, Krajcberg busca na natureza a superação do trauma. Trauma da violência desenfreada do ser humano. Ao encontrar cura para seu trauma na exuberância da natureza brasileira, Krajcberg mais uma vez se defronta com outra violência do ser humano: as queimadas e o desmatamento da Floresta Amazô- mantém "viva" na forma de madeira. O artista utiliza como matéria-prima troncos, cipós e palmeiras ou outros elementos que seleciona após as queimadas.

Em conversa com João Meirelles Filho [2015], Krajcberg relata querer sua obra bruta. Não quer fazer arte para agradar. Sua intenção é chamar a atenção para a devastação que está sendo feita: "Agora eu gostaria de entrar em uma forma mais bruta, eu acho que tou [sic] entrando um pouquinho no bonito no meu trabalho... Começar a agradar, e eu não gosto disso. Gostaria mais de ser EU como eu sou, o impacto da arte bruta. A arte bruta natural, é nisso que eu quero chegar agora." [KRAJCBERG, 1984, apud MEIRELLES FILHO, 2015, p. 24]. 
Durante a Guerra, sua família foi dizimada. Krajcberg foi o único que sobreviveu, assim como em seus trabalhos; os galhos e ramos calcinados, recolhidos após a queimada, são os que sobreviveram sem tornarem-se cinzas. Parece desse modo que a conexão dos sobreviventes, que assumem para si o poder denunciativo da violência/tragédia vivenciada, tornam-se vestígios da sobrevivência, marcados pela dramaticidade da violência a que foram expostos. Nesse sentido, a obra e vida de Krajcberg se misturam. E ele faz questão de enfatizar isso, afirmando-se como um revoltado com as atrocidades do ser humano. "Minha obra é um manifesto. O fogo é a morte, o abismo. $\bigcirc$ fogo me acompanha desde sempre. A destruição tem formas. Eu procuro imagens para meu grito de revolta." [KRAJCBERG, apud BINI, 2011, p. 91]

Com sua vida marcada por grandes perdas, as biografias sobre o artista relatam que ele chegou no final da década de 1940 ao Brasil, sozinho e sem dinheiro. Primeiro, aportando na cidade do Rio de Janeiro e depois transferindo-se para São Paulo, posteriormente para o Paraná e de lá retornando para o Rio de Janeiro. Mas também morou em Itabirito, Minas Gerais e, por fim, entre idas e vindas da Europa, fixou-se na década de 1970 na cidade de Nova Viçosa, no sul da Bahia.
Krajcberg encontrou-se com a natureza brasileira e com ela sentiu sua vitalidade recuperar-se. Assim, desde os primeiros anos no Brasil, a obra de Krajcberg relacionava-se diretamente com a natureza. Em 1951, Krajcberg ajudou na montagem da $1^{a}$ Bienal de São Paulo, e também foi escolhido pelo júri para expor suas pinturas. E em 1957, ganhou o prêmio de melhor pintor nacional da 4 a Bienal de São Paulo. Já em 1977, a edição da Bienal sofrera mudanças. Seu diretor artístico desde o início, Francisco Matarazzo Sobrinho, o Ciccilo, falecera seis meses antes da exposição. A mostra teve seu formato alterado, das representações nacionais passaram a separar os artistas por temas. "Todas as manifestações visuais que envolviam a ecologia, o problema da paisagem, do meio natural - integrado ou não ao meio urbano e viário -, as reservas, a destruição e a conservação dessa mesma paisagem, agrupavam-se sob o tema A Recuperação da Paisagem." [AMARANTE, 1989, p. 251] 
Os trabalhos de Krajcberg estavam reunidos sob este tema, afinal ele foi "um dos primeiros artistas brasileiros a se preocupar com a natureza, muitos anos antes de o termo "ecologia" ser manchete nos jornais e assunto nos telejornais. Suas esculturas, transposições de formas criadas pela própria natureza, sempre estiveram livres das amarras de todos os ismos." [AMARANTE, 1989, p. 251]. A relação que o artista estabeleceu com a natureza perpassava seu envolvimento com as tendências da arte. Krajcberg manteve-se fiel à sua luta, tendo sua obra largamente exibida em exposições nacionais e internacionais. Inclusive, ele recebeu o prêmio da Cidade de Veneza, durante a Bienal de Veneza de 1967. Participou de mais de 10 edições da Bienal de São Paulo. Em sua biografia, é marcada a consolidação de seu envolvimento com a natureza e amadurecimento de sua poética. A prática artística de Krajcberg passou por alterações conforme sua ânsia por um maior estreitamento na sua relação com a natureza.

\footnotetext{
Minha obra é uma longa luta amorosa com a natureza, eu podia mostrar um fragmento dessa beleza. E assim fiz. Mas não posso repetir esse gesto até o infinito. Como fazer meu esse pedaço de madeira? Como exprimir minha emoção? Mudei minha obra sempre que senti ser preciso. Mudei? Não. Apenas encontrei uma outra natureza. Cada vez que ia a lugares diferentes, minha obra mudava. Eu recolhia troncos mortos nos campos mineiros e com eles fiz minhas primeiras esculturas, colocando-os com a terra. Eu queria thes dar uma nova vida. Foi minha fase "naïve" e romântica. [KRAJCBERG, 2003, p. 30]
}

Em 1978, Krajcberg com Sepp Baendereck e Pierre Restany percorrem a bacia do Alto Rio Negro, a Noroeste do Amazonas, expedição da qual criam o Manifesto do Rio Negro, ou Manifesto do Naturalismo Integral, nas palavras de Restany [1987]: "Foi então que eu redigi o Manifesto do Naturalismo Integral, e Frans percebeu antes de mais nada essa mensagem da natureza como uma disciplina do pensamento, uma reordenação do espírito e dos sentidos em relação ao espaço-tempo mecânico da civilização urbana." [...] [RESTANY, 1987, p. 13]. A partir dessa viagem, que dá ênfase a sua fase ambientalista mais acirrada, Krajcberg direciona sua produção para as questões da Amazônia. "É para a Amazônia que seu manifesto se dirige, o manifesto da Amazônia em seu contexto planetário." [MEIRELLES FILHO, 2015, p. 15]. João C. S. Meirelles Filho [2015] analisa que a visita de 1978 à Amazônia tenha marcado a produção artística de Krajcberg. Contudo, foram as visitas à Juruena, no estado do Mato Grosso, que deram outra intensidade a sua produção artística.

\footnotetext{
A viagem à fronteira pioneira, ao Brasil Queimado, provoca-o [incendeia-o e o chamusca] de tal maneira, que sua obra se consolida e alcança o apelo internacional que almeja. Até então, a Amazônia que conhecera era a Amazônia Fluvial, em certa maneira, idílica e bucólica, com apenas feridas, aqui e ali, na
} 
floresta. No norte de Mato Grosso, e nos percursos até Jurvena, verá a destruição em grande escala, o corpo da Amazônia queimado; e, mais, conviverá com este processo, diferentemente do papel de espectador-contemplador nas viagens fluviais na década de 1970. Em Jurvena ele age, entra na mata, na queimada, busca objetos, fotografa, participa do processo criativo com a Natureza. [MEIRELLES FILHO, 2015, p. 17]

Várias expedições levaram Frans Krajcberg a fazer coletas de materiais, resultantes das queimadas, no norte do Mato Grosso. João Meirelles Filho [2015] relata como acompanhou o artista na busca de vestígios e testemunhos para a criação de suas obras. [Fig. 2] Após as coletas, Krajcberg trabalhava com esses materiais em seu sítio, Natura, em Nova Viçosa, Bahia. Em seu ateliê, ele intensificava a dramaticidade de cada material recolhido utilizando a pintura com pigmentos naturais, algumas vezes retorcendo, queimando mais um pouco, instalando base e/ou sombra, para com isso intensi- ficar o apelo que pretendia apresentar como seu "grito" de revolta contra a destruição.

Frans nos exige enxergar como banalizamos e ignoramos A Queimada. Quão é importante para nós, brasileiros, subjugar a floresta, controlar a natureza, a queimada como meio, caminho. E, como, neste processo, relevamos a presença dos povos originais e das populações tradicionais, como desperdiçamos a madeira e os recursos naturais. Depois de conhecer a obra de Frans, ninguém sentirá A Queimada da mesma maneira. [MEIRELLES FILHO, 2015, p. 17]

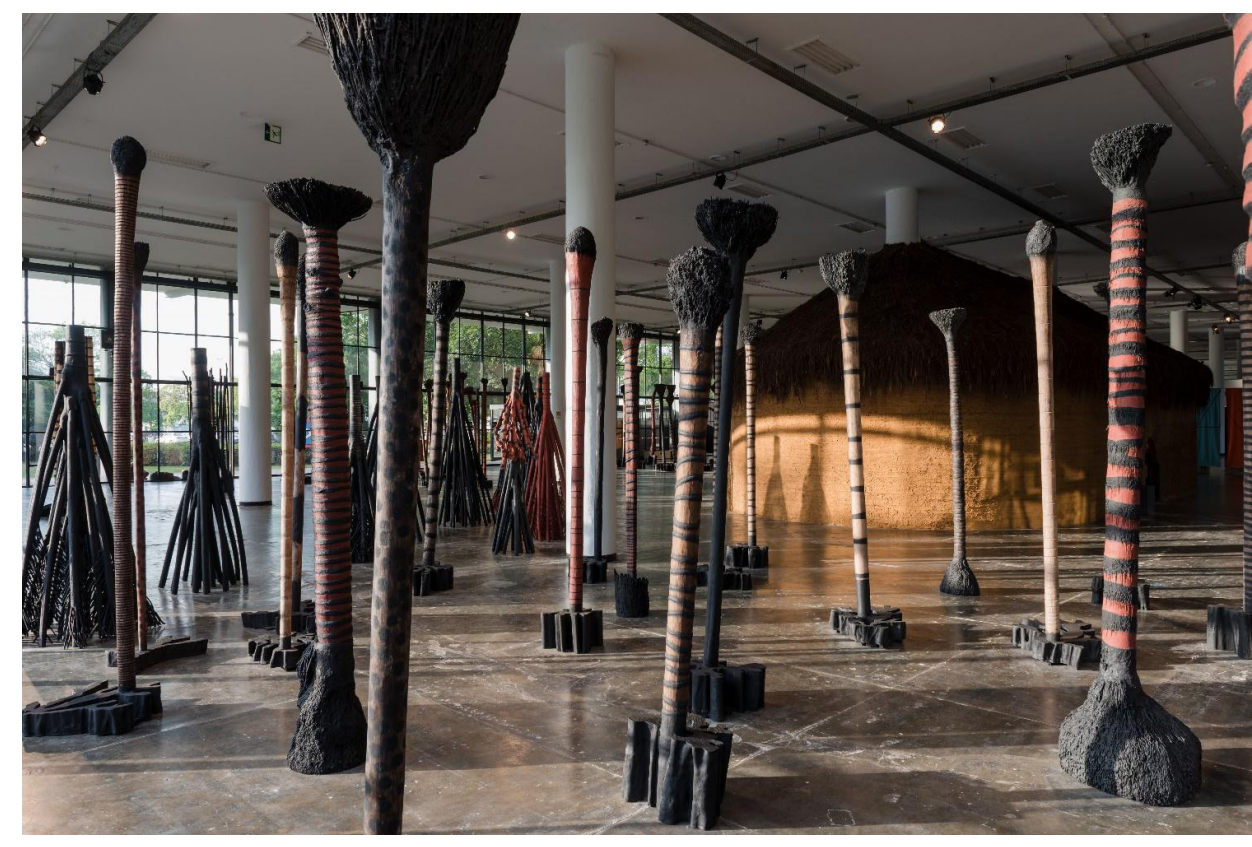

Fig. 2 - Frans Krajcberg, Sem título [Coqueiros], s/d.

Esculturas de madeira de queimada e pigmentos naturais. 62 peças, dimensões variadas. Fonte: Leo Eloy [EstúdioGaragem], cortesia Fundação Bienal de São Paulo. 
Não escrevo, encontro imagens: essa é minha maneira de trabalhar. Meu alfabeto são as imagens vistas nas obras expostas, que devem, principalmente, ser ponto de partida para uma reflexão mais abrangente sobre o homem e sua relação com o meio ambiente... O planeta exige isso de nós. [KRAJCBERG, 2003, p. 34].
1 O presente trabalho foi realizado com apoio da Coordenação de Aperfeiçoamento de Pessoal de Nível Superior - Brasil [CAPES] - Código de Financiamento 001 .

Neste momento, o planeta exige tantas coisas nós: revisarmos nosso consumo, nossos modos de vida, nossa relação exploratória com a natureza, nossas escolhas diárias que impactam diretamente nas paisagens ao nosso redor, dentre tantas outras ações que o planeta clama em tempos apocalípticos. momento atual, de isolamento social, possibilita uma autorreflexão sobre os impactos de cada ação e dos percursos de nossas escolhas diárias. A tomada de consciência de todos esses impactos não, necessariamente, implica em uma mudança real de hábitos. Requer constante vigília e autodeterminação.

Para resistir e sobreviver, experiências que Krajcberg viveu intensamente, é necessário envolver-se com a Natureza. Esse é o canto que sobressairá ao escuro. Ao compreendermos que somos parte da Natureza e não proprietários, nos juntaremos à revolta de Krajcberg contra o desmatamento e destruição dos biomas naturais de todo o planeta. E assim homenagearemos sua memória, reconheceremos a luta de sua vida e realmente entenderemos o sentido de sua poética. <
2 "O Antropoceno [ou que outro nome se lhe queira dar] é uma época, no sentido geológico do termo, mas ele aponta espécie. Embora tenha começado conosco, muito provavelmente terminará sem nós: o Antropoceno só deverá dar lugar a uma outra época geológica muito depois de termos desaparecido da face da Terra. Nosso presente é o Antropoceno; este é o nosso tempo. Mas este tempo presente vai se revelando um presente sem porvir, um presente passivo, portador de uma arma geofísica que está inteiramente fora de nosso alcance anular o que torna tanto mais urgente e imperativa a tarefa de sua mitigação: [...]" [DANOWSKI; VIVEIROS DE CASTRO, 2014, p. 16]. 3 Ver WALLACE, Rob. Big Farms Make Big Flu: Dispatches on Influenza, Agribusiness, and the Nature of Science. NY: NYC Press. 2016. [Em português: WALLACE, Rob. Pandemia e agronegócio: doenças infecciosas, capitalismo e ciência. Tradução: Allan Rodrigo de Campos Silva. São Paulo: Elefante. 2020.]. 4 Rob Wallace pesquisou a monocultura da produção de dendê na África e a relacionou como uma das causas da disseminação do vírus do Ebola. Ver WALLACE, Rob; WALLACE, Rodrick. Ebola, doença do colonialismo. Trad. Simone Paz. Outras Palavras. [s. I.], 2019. Disponível em https:/ / outraspalavras. net/descolonizacoes/ebola-doenca-do-colonialismo/ Acesso em 15/7/2020. para o fim da "epocalidade" enquanto tal, no que concerne à 
5 Confira a reportagem publicada no jornal El País: MEGÍA, Carlos. Bilionários se preparam para o fim da civilização. El País, Internacional. [s. I.], 03 de agosto de 2020. Disponível em https://brasil.elpais.com/internacional/2020-08-03/bilionarios-se-preparam-para-o-fim-da-civilizacao.html Acesso em 30 ago./2020.

6 Recentemente também foi publicada no Jornal Folha de São Paulo uma notícia sobre o aumento da renda dos pecuaristas com a pandemia. [TOLEDO, Marcelo; BARAN, Katna. Agronegócio bate recordes e amplia mercado apesar de pandemia de Covid. Jornal Folha de São Paulo, Mercado. Ribeirão Preto e Curitiba, 08 de agosto de 2020. Disponível em https:/ / www l. folha.uol.com.br/mercado/2020/08/agronegocio-bate-recordes-e-amplia-mercado-apesar-de-pandemia-de-covid.shtml Acesso em 30/8/2020]. Há uma crítica bastante contundente sobre o assunto no Blog da Editora Elefante, na qual Tadeu Breda enfatiza os riscos da agroindústria com as novas pandemias, baseado nos estudos de Rob Wallace. [Ver BREDA, Tadeu. Nossa seleção industrial de doenças. Blog da Editora Elefante. [s. I.], 22 de agosto de 2020. Disponível em https://www. editoraelefante.com.br/nossa-selecao-industrial-de-doencas/. Acesso em 30/8/2020].

7 Sobre o acontecimento na data de 19 de agosto de 2019, ver TOLEDO, Karina. Pesquisadores descrevem trajetória do "rio de fumaça" que escureceu São Paulo. Agência FAPESP, Fundação de Amparo a Pesquisa de São Paulo. [s. I.], 22 de agosto de 2019. Disponível em https:/ /agencia.fapesp.br/pesquisadores-descrevem-trajetoria-do-rio-de-fumaca-que-escureceu-sao-paulo/31280/ Acesso em 30/8/2020.
8 Segundo a Enciclopédia do Itaú Cultural, Krajcberg participou das seguintes edições da Bienal Internacional de São Paulo: 1 1 $^{a}, 3^{a}, 4^{a}, 6^{a}, 7^{a}, 8^{a}, 14^{a}, 15^{a}, 20^{a}$, Brasil $+500,30$ $\times$ Bienal, e 32 ${ }^{\circ}$. Ver FRANS Krajcberg. In ENCICLOPÉDIA Itaú Cultural de Arte e Cultura Brasileiras. São Paulo: Itaú Cultural, 2020. Disponível em http://enciclopedia.itaucultural.org.br/ pessoa 10730/frans-krajcberg. Acesso em 28/8/2020. Verbete da Enciclopédia. 
34a BIENAL DE SÃO PAULO terá início em fevereiro de 2020 com mostras individuais e performances. Bienal de São Paulo. [São Paulo], 20 de setembro de 2019. Disponivel em http://www.bienal.org.br/post/7203. Acesso em 30/8/2020.

AMARANTE, Leonor. As Bienais de São Paulo, 1951-1987. São Paulo: Projeto. 1989.

BINI, Fernando. A contribuição do fogo nas artes visuais. In SCOVINO, Felipe. Frans Krajcberg. Texto Felipe Scovino, Fernando Bini, Pierre Restany. Tradução Grupo Solución. São Paulo: Arauco Editora. 2011. p. 53-104

DANOWSKI, Déborah; VIVEIROS DE CASTRO, Eduardo. Há mundo por vir? Ensaio sobre os medos e os fins. Florianópolis: Cultura e Barbárie : Instituto Socioambiental, 2014.

KIYOMURA, Leila. As incertezas povoam a 32a Bienal de São Paulo. Jornal da USP, São Paulo, Cultura, 14 de setembro de 2016. Disponível em https://jornal.usp.br/cultura/as-incertezas-povoam-a-32a-bienal-de-sao-paulo/. Acesso em 30/8/2020.

KRAJCBERG, Frans. Paisagens ressurgidas. Curadoria: Denise Mattar. São Paulo: Centro Cultural Banco do Brasil, 2003.

KRAJCBERG, Frans. Um vídeo com Frans Krajcberg. São Paulo: Fundação Bienal de São Paulo, 2016. Vídeo, Online, 12", color. Disponível em http://www.bienal.org.br/texto/2740. Acesso em 30/8/2020. 
MEIRELLES FILHO, João Carlos de Souza. Grito pela Amazônia: o encontro de Frans Krajcberg e Thiago de Mello. Publicado no website O EcoAmazônia, 05 de maio de 2011. Disponível em https://www.academia. edu/8399993/Grito_pela_Amazônia_o_encontro_de_Frans_Krajcberg_e_Thiago_de_Mello_2011_Acesso em 30 ago./2020.

MEIRELLES FILHO, João Carlos de Souza. O manifesto do artista brasileiro Frans Krajcberg. Publicado no Portal Envolverde, 27 de janeiro de 2015. Disponível em https://www.academia.edu/10395653/O_manifesto_do_artista_brasileiro_Frans_Krajcberg_2015_Acesso em 30 ago./2020.

OLIVEIRA, Uillian Trindade. Frans Krajcberg: história de vida e processo de criação. 2015. Tese [Doutorado em Educação] - Centro de Educação, Universidade Federal do Espírito Santo, Vitória, 2015.

RESTANY, Pierre. Uma planta entre plantas. In KRAJCBERG, Frans. Natura. Textos de Antônio Houaiss, Pierre Restany, João Meirelles Filho. Rio de Janeiro: Editora Index. 1987. p.13-15

SCOVINO, Felipe. Frans Krajcberg. In SCOVINO, Felipe. Frans Krajcberg. Texto Felipe Scovino, Fernando Bini, Pierre Restany. Tradução Grupo Solución. São Paulo: Arauco Editora. 2011. p. 25-47.

VISCONTI, Jacopo Crivelli; MIYADA, Paulo; ZACCAGNINI, Carla; STOCCHI, Francesco; ESTÉVEZ, Ruth. Correspondência \#8. 34a Bienal de São Paulo. [São Paulo], 08 de julho de 2020. Disponível em http://www. bienal.org.br/post/8099. Acesso em 30/8/2020.

VOLZ, Jochen. Incerteza Viva. In VOLZ, Jochen; PRATES, Valquíria [org.] Incerteza Viva - processos artísticos e pedagógicos - 32a Bienal de São Paulo. São Paulo: Fundação Bienal de São Paulo, 2016b. p. 07-11.

VOLZ, Jochen. Jornadas Espirais: Incerteza Viva. In VOLZ, Jochen; REBOUÇAS, Júlia [org.]. 32a Bienal de São Paulo, Incerteza Viva - Catálogo. São Paulo: Fundação Bienal de São Paulo, 2016a. p. 21-27. 